\title{
Distension thoracique
}

\section{Thoracic distension}

\section{P. Ray}

Reçu le 21 novembre 2011 ; accepté le 7 janvier 2012

(C) SFMU et Springer-Verlag France 2012

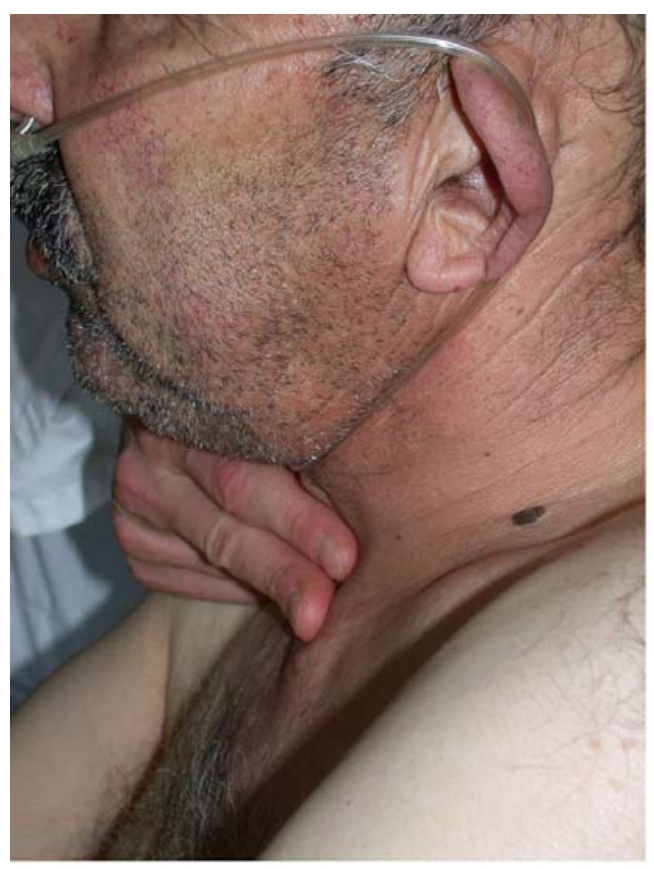

Fig. 1 Distension thoracique

Le diagnostic de maladie obstructive bronchique est difficile en urgence. L'existence d'une diminution de la distance entre le bord supérieur de la trachée et le cartilage thyroïde $(<5 \mathrm{~cm})$, associée à un tabagisme supérieur à 40 paquets/ année chez un patient de plus de 45 ans est très fortement évocateur d'obstruction bronchique post-tabagique avec un ratio de vraisemblance positif de plus 58 (Fig. 1) [1]. De plus, la distension thoracique est généralement associée à une descente inspiratoire de la trachéee (signe de Campbell). Cet élément dynamique, conséquence des dépressions pleurales importantes qui sont produites par les patients distendus, permet de distinguer un simple « cou court » d'une distension thoracique.

\section{Référence}

1. Straus SE, McAlister FA, Sackett DL, et al (2000) The accuracy of patient history, wheezing, and laryngeal measurements in diagnosing obstructive airway. JAMA 283:1853-7

P. Ray $(\square)$

Service d'accueil des urgences,

Groupe hospitalier Tenon-Saint Antoine,

4, rue de la Chine, F-75020 Paris,

Université Pierre et Marie Curie-Paris 6, France

e-mail : patrick.ray@tnn.aphp.fr 